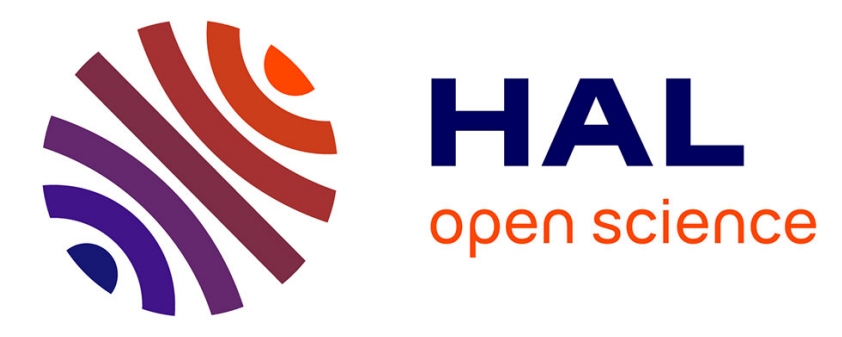

\title{
Pulse generator battery life in deep brain stimulation: out with the old... in with the less durable?
}

\author{
Emmanuel de Schlichting, Guillaume Coll, Julien Francisco \\ Zaldivar-Jolissaint, Jerome Coste, Ana Raquel Marques, Aurélien Mulliez, \\ Franck Durif, Jean-Jacques Lemaire
}

\section{To cite this version:}

Emmanuel de Schlichting, Guillaume Coll, Julien Francisco Zaldivar-Jolissaint, Jerome Coste, Ana Raquel Marques, et al.. Pulse generator battery life in deep brain stimulation: out with the old... in with the less durable?. Acta Neurochirurgica, 2019, 161 (10), pp.2043-2046. 10.1007/s00701-01904043-8 . hal-02277177

\section{HAL Id: hal-02277177 \\ https://hal.science/hal-02277177}

Submitted on 5 Sep 2019

HAL is a multi-disciplinary open access archive for the deposit and dissemination of scientific research documents, whether they are published or not. The documents may come from teaching and research institutions in France or abroad, or from public or private research centers.
L'archive ouverte pluridisciplinaire HAL, est destinée au dépôt et à la diffusion de documents scientifiques de niveau recherche, publiés ou non, émanant des établissements d'enseignement et de recherche français ou étrangers, des laboratoires publics ou privés. 


\section{Pulse generator battery life in deep brain stimulation:}

\section{out with the old... in with the less durable?}

Emmanuel de Schlichting ${ }^{1, *}$, Guillaume Coll ${ }^{2,3}$, Julien Francisco Zaldivar-Jolissaint ${ }^{1}$, Jérôme Coste $^{2,3}$, Ana Raquel Marques ${ }^{4,5}$, Aurélien Mulliez ${ }^{6}$, Franck Durif ${ }^{4,5}$, Jean-Jacques Lemaire ${ }^{2,3}$

1. Service de Neurochirurgie, Centre Hospitalier Universitaire de Grenoble-Alpes (CHUGA) La Tronche, France

2. Service de Neurochirurgie, Centre Hospitalier Universitaire de Clermont Ferrand, Clermont Ferrand, France

3. IP - Institut Pascal - Clermont Auvergne, Aubière, France

4. Service de Neurologie, Centre Hospitalier Universitaire de Clermont Ferrand, Clermont Ferrand, France

5. Npsy-Sydo - Neuro-Psycho Pharmacologies des Systèmes Dopaminergique sous-corticaux, Clermont Ferrand, France

6. Unité de Biostatistiques, Délégation Recherche Clinique et Innovation, Centre Hospitalier Universitaire de Clermont Ferrand, Clermont Ferrand, France

\section{Abstract}

Background

Battery life of the most commonly used implantable pulse generators in deep brain stimulation is limited. Device replacement is costly and may expose patients to additional risks. Driven by the observation that in our experience newer generation devices seemed to need earlier replacement than the older generation, we aimed to retrospectively analyze the battery life of two generations of nonrechargeable devices, manufactured by a single company (Medtronic, USA).

\section{Methods}

Battery life of 281 devices in 165 patients was taken into account for data analysis. This represented 243 older generation devices (Kinetra and Soletra) and 38 newer generation devices (Activa).

Results

The battery life of older generation stimulators was 2-fold longer than the newer generation.

Conclusions

Newer devices are more versatile than the older generation. Their battery life is however significantly shorter. Development of next-generation devices needs to address this issue in order to limit health risks and reduce financial costs.

\section{Keywords}

DBS, Battery life, Implantable pulse generator 


\section{Introduction}

Deep brain stimulation (DBS) has become a common neurosurgical therapeutic strategy for managing complex neurological disorders including movement disorders, depression, epilepsy, and other diseases [6]. When indicated, it is a remarkably effective treatment that relies on the premise that electrical stimulation in a specific target in the brain may induce local and distant electrical and neurochemical changes, thus providing a therapeutic effect $[1,4]$.

The medical device used in DBS can be broken down into three components: (1) a DBS lead which is precisely implanted in the targeted brain area, (2) a cable extension, and (3) an implantable pulse generator (IPG), usually placed in the subclavicular or abdominal subcutaneous tissue. The IPG includes a battery necessary to create the electrical impulse.

Many developments have increased the versatility and complexity of newer devices (e.g., adjustable stimulating parameters, memory features) while also allowing device size reduction and increasing significantly the lifespan of the battery. Battery exhaustion occurs after a few years and device replacement through surgical revision is needed. Currently, rechargeable devices are available, but the most frequently implanted IPGs remain the non-rechargeable ones.

The longevity of the IPG battery depends on the device characteristics and electrical stimulation settings, which vary depending on various clinical parameters such as the underlying disease process, the stimulation target, and the age of the patient. Since DBS is an invasive and costly procedure [2], identification of factors associated with greater longevity of the battery is needed. Driven by the observation that in our experience newer generation devices seemed to need earlier replacement than the older generation, we aimed to retrospectively analyze the battery lifetime of different kinds of nonrechargeable devices, manufactured by a single company (Medtronic, USA) in patients who underwent deep brain stimulation for various movement disorders at our center.

\section{Methods and materials}

\section{Population}

In the present retrospective analysis, we initially included all patients who underwent a DBS procedure with primary electrode, extension, and IPG implantation at Clermont-Ferrand University Hospital from December 1995 to August 2016; and analyzed the battery lifetime of the IPG upon each device replacement. An ethical certificate was obtained at our local ethics committee for approval of use of patient data and medical records. Collected data parameters included patient's gender and age at implantation, diagnosis, brain target, the date of the implantation, the date of IPG replacement, IPG model, the stimulation voltage, the anatomical positioning of the IPG, and the presence of any extra extensions or an adapter.

The battery lifespan was defined as the period between the surgical implantation and the date of device removal for battery depletion. The threshold for battery depletion was defined according to the literature and manufacturer guidelines [3].

We excluded the devices which were still operational as of August 2016, the devices replaced within the first year of implantation, the devices replaced due to surgical complications, the devices with 
missing collection data parameters, and the devices with missing patient follow-up or in cases of patient's death.

\section{Characteristics of the devices}

We compared the battery lifespan of four different types of IPGs manufactured by one single company (Medtronic, USA).

The older generation of IPGs analyzed includes the Kinetra ${ }^{\circledR}$, a 8-contact neurostimulator for two DBS-leads, and the Soletra ${ }^{\circledR}$, a 4-contact neurostimulator for one DBS-lead. The newer generation of IPGs analyzed includes the Activa ${ }^{\circledR}$ PC, a programmable 2-lead 16-contact neurostimulator, and Activa ${ }^{\circledR}$ SC, a single lead 8-contact stimulator.

\section{Statistical analysis}

Statistics were computed using GraphPad Prism, Stata 12 (Stata Corp, College Station, TX, USA) and R-software (version 3.3.0).

Time to battery depletion was analyzed using survival methods. In univariate analysis, we plotted Kaplan-Meier curves and compared groups using log-rank test. In multivariate analysis, we used a mixed effects cox model to analyze the effects of IPG generation (new vs old), voltage, diagnosis, location, and prior-implantation. Results are shown as adjusted hazard ratio and their $95 \%$ confidence interval. The proportional hazard assumptions were checked graphically and using the Schoenfeld residuals tests, and were found to be satisfactory. All tests were two-sided. A p value $<5 \%$ was considered significant.

\section{Results}

\section{Baseline characteristics of the population}

Five hundred seventy non-rechargeable IPGs were implanted in 271 patients from December 1995 to August 2016. We excluded implanted IPGs where the device was still functional or the patient died before battery depletion, implantations where the device was not documented or the patient was lost on follow-up, and 3 devices because of infectious complication. Two hundred eighty-one devices remained included representing 165 patients. The primary device implantation indication was Parkinson's disease (233 devices), followed by essential tremor (30 devices) and dystonia (18 devices). One hundred sixty-five were primary implantations and 116 were IPG replacements. This represented 243 older generation IPGs (203 Kinetra and 40 Soletra) and 38 newer generation IPGs (35 Activa PC and 3 Activa SC).

\section{Univariate analysis}

As expected, stimulation voltage was inversely correlated with battery lifetime $(p<0.001)$. The median battery lifetime was 2-fold longer for the Kinetra and Soletra (28 months) devices than the Activa PC and Activa SC devices (57 months) $(\mathrm{p}<0.0001)$ (Fig. 1a, b). This was valid when comparing both primo-implantations and replacements independently $(\mathrm{p}<0.001)$. 

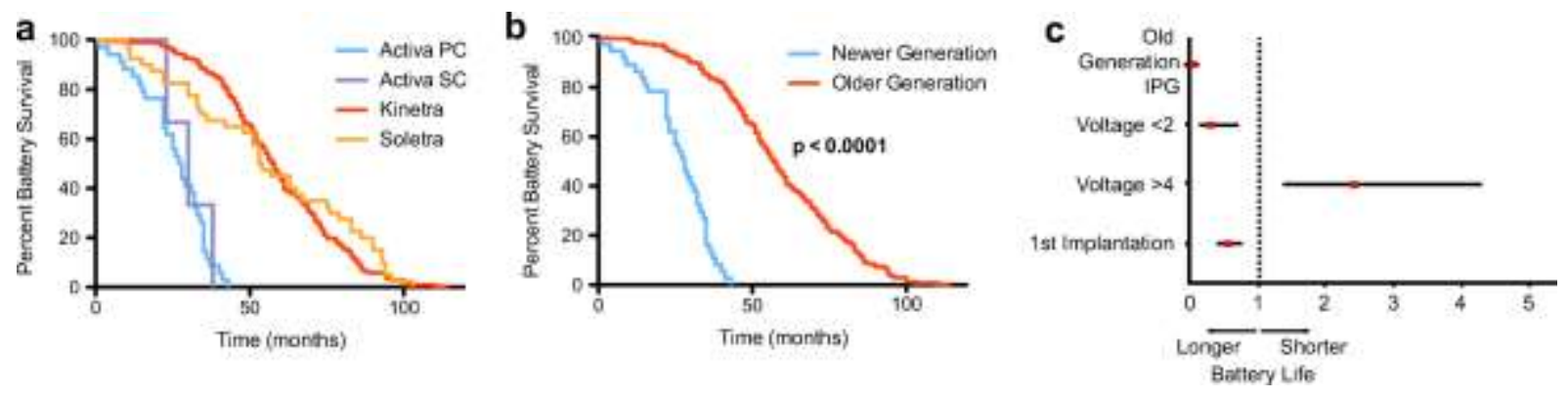

Figure 1. a Kaplan-Meir survival curve of all IPGs analyzed. b Kaplan-Meir survival curve of old-vs new-generation IPGs. $c$ Odds ratio graph

\section{Multivariate analysis}

As many factors have been shown to influence the battery lifetime of IPGs, we used a multivariate analysis, mixed effects cox model to take into account the effects of IPG generation (new vs old), voltage, diagnosis, and prior-implantation.

Multivariate analysis confirmed that IPG generation was the strongest factor influencing battery life in our cohort (Fig. 1c) $(\mathrm{HR}=12.77,95$ CI 6.20-16.34, $\mathrm{p}<0.001)$.

\section{Discussion}

Our initial observation that newer generation IPGs needed to be replaced sooner was confirmed statistically. This is particularly striking, as the difference is in fact 2-fold and IPG generation was the most important independent influencing factor of battery life in our cohort. Two recent articles have found these similar results $[5,11]$ and corroborate two previously published papers [7, 8].

Newer generation IPGs offer more versatile stimulation programming, with the caveat of shorter battery lifetime. Implantation of a new generation non-rechargeable IPG requires more device replacements. This exposes patients of an already frail population to increased surgical risks and may increase healthcare costs significantly. Furthermore, DBS patients may become stimulation-dependent. In severe Parkinson's disease patients, stimulation withdrawal may even precipitate life-threatening akinetic crisis $[9,10]$. This dependency makes DBS indispensable for many, especially given the progressive character of the disease.

It is of paramount importance that the industry acknowledges this problem. Rechargeable IPGs have not provided a solution as they are more expensive and impose constraints that few patients are willing to have. Next-generation IPGs cannot be less durable than their predecessors, as this unequivocally increases the risk of treatment complications. 


\section{Conflict of interest}

The authors declare that they have no conflict of interest.

\section{Ethical approval}

All procedures performed in studies involving human participants were in accordance with the ethical standards of the institutional and/or national research committee (name of institute/committee) and with the 1964 Helsinki Declaration and its later amendments or comparable ethical standards.

Statement of informed consent

This is a retrospective study. Formal consent is not required.

\section{References}

1. Ashkan K, Rogers P, Bergman H, Ughratdar I (2017) Insights into the mechanisms of deep brain stimulation. Nat Rev Neurol 13(9):548-554

2. Becerra JE, Zorro O, Ruiz-Gaviria R, Castañeda-Cardona C, Otálora-Esteban M, Henao S, Navarrete S, Acevedo JC, Rosselli D (2016) Economic analysis of deep brain stimulation in Parkinson disease: systematic review of the literature. World Neurosurg 93:44-49

3. Halpern CH, McGill KR, Baltuch GH, Jaggi JL (2011) Longevity analysis of currently available deep brain stimulation devices. Stereotact Funct Neurosurg 89(1):1-5

4. Herrington TM, Cheng JJ, Eskandar EN (2016) Mechanisms of deep brain stimulation. J Neurophysiol 115(1):19-38

5. Israeli-Korn SD, Fay-Karmon T, Tessler S, Yahalom G, Benizri S, Strauss H, Zibly Z, Spiegelmann R, Hassin-Baer S (2019) Decreasing battery life in subthalamic deep brain stimulation for Parkinson's disease with repeated replacements: just a matter of energy delivered? Brain Stimul. https://doi.org/10.1016/j.brs.2019.02.008

6. Karas PJ, Mikell CB, Christian E, Liker MA, Sheth SA (2013) Deep brain stimulation: a mechanistic and clinical update. Neurosurg Focus 35(5):E1

7. Niemann M, Schneider G-H, Kühn A, Vajkoczy P, Faust K (2018) Longevity of implantable pulse generators in bilateral deep brain stimulation for movement disorders. Neuromodulation J Int Neuromodulation Soc 21(6):597-603

8. Park K, Lim YH, Jang M, Kim A, Kim H-J, Paek SH, Jeon B (2018) Battery life matters in deep brain stimulation. Stereotact Funct Neurosurg 96(1):65-66

9. Rajan R, Krishnan S, Kesavapisharady KK, Kishore A (2016) Malignant subthalamic nucleusdeep brain stimulation withdrawal syndrome in Parkinson's disease. Mov Disord Clin Pract 3(3):288-291

10. Reuter S, Deuschl G, Berg D, Helmers A, Falk D, Witt K (2018) Life-threatening DBS withdrawal syndrome in Parkinson's disease can be treated with early reimplantation. Parkinsonism Relat Disord 56:88-92

11. Sette AL, Seigneuret E, Reymond F, Chabardes S, Castrioto A, Boussat B, Moro E, François P, Fraix V (2019) Battery longevity of neurostimulators in Parkinson disease: a historic cohort study. Brain Stimul Basic Transl Clin Res Neuromodulation. 